\title{
In-situ spectral emissivity measurement of alloy steels during annealing in controlled atmosphere
}

\author{
by S. H. Ham $^{1,2,}$ M. Ferté ${ }^{1}$, G.Fricout ${ }^{1}$, L. Depalo ${ }^{1}$ and C. Carteret $^{2}$ \\ ${ }^{1}$ ArcelorMittal Global R\&D, Voie Romaine, Maizières-lès-Metz, France, grace.ham-partner@arcelormittal.com \\ 2 L.C.P.M.E, UMR 7564, CNRS, Université de Lorraine, Villers-lès-Nancy
}

\begin{abstract}
A laboratory set-up to simulate the annealing conditions of a hot-dip galvanizing line is employed to track the radiometric property evolution of alloy steel during the heating and soaking. A variation of the dew point of the annealing atmosphere yields different morphology and chemical composition of the surface oxides. In-situ emission spectra are acquired by a LWIR spectrometer $(8-12 \mu \mathrm{m})$ and post-annealed sample characterization is performed using field emission scanning electron microscope (FE-SEM), energy-dispersive X-ray spectroscopy (EDX), atomic force microscopy (AFM) and Fourier transform infrared (FTIR) spectroscopy. It is found that apart from the chemical composition, surface roughness which is caused by the oxide morphology and the distribution of oxide in the depth contribute to the overall emissivity variation.
\end{abstract}

\section{Introduction}

After the continuous annealing stage on a galvanization line of steel production, the mechanical properties of steel are enhanced and the native iron oxide is reduced in the controlled atmosphere of $\mathrm{H}_{2}+\mathrm{N}_{2}$ to attain a metallic surface to form intermetallic bond with the zinc coating. This step gives rise to the desired mechanical properties and lays ground for good adherence of the coating. Compared to conventional carbon-iron steel, high performance steels such as transformation induced plasticity (TRIP), dual phase (DP) and high formability (HF) grades have higher percentage of alloying elements such as $\mathrm{Mn}, \mathrm{Al}$, Si. These alloying elements enable steels to have the required mechanical properties in order to fulfill the demand of lightweight and safety in the automotive industry. However, selective oxidation of the more reactive alloying elements occurs in the controlled atmosphere, forming barriers for the intermetallic bond with the zinc coating [1], [2]. This calls for a need to detect selective oxides for quality control purpose.

On the other hand, the thermodynamics and kinetics of the oxidation process is determined by the parameters of the atmosphere such as the partial pressure of water vapour (represented by dew point), oxygen, hydrogen as well as the temperature [1]-[3]. The partial pressure of oxygen is balanced by the $\mathrm{H}_{2}-\mathrm{H}_{2} \mathrm{O}$ reaction at equilibrium conditions. From the kinetics perspective, the formation of external and internal oxide is governed by the relative diffusion rates of the alloying elements and oxygen. Wagner's model and its extensions describing the oxidation process could be found in [4]. According to these models, if the inward diffusion of oxygen exceeds the outward diffusion of alloying elements, internal oxidation takes place, whereas an external oxidation requires the outward diffusion of alloying elements to be faster than the inward diffusion of oxygen. To study these two cases, the different atmospheric conditions pertaining to that are to be reproduced in the laboratory during the annealing of steel samples.

Although the detailed study of the chemical composition of selective oxides using X-ray photo-electron spectroscopy (XPS) and scanning Auger microprobe (SAM) analysis yield precise physicochemical information [2], [5], it remains an ex-situ method using laboratory instruments that are not suitable for the implementation on the production line. In this study, a more industry-adapted instrument such as a non-cooling spectrometer is applied during the laboratory annealing experiments to carry out in-situ measurements.

The emissivity values of steel have been used as a parameter in pyrometers for accurate temperature measurement in the industrial environment. Del campo et al. [6] studied the emissivity of steel in relation to iron oxidation. Recently, Shi et al. [7] published the spectral emissivity of Usibor ${ }^{\circledR}$ with Al-Si coating from in-situ measurement in NIR. Wen et al. [8] explored the effects of surface roughness on the emissivity of aluminium alloys. In general, spectral emissivity is a function of temperature, surface chemical composition, roughness and surface oxidation state [7].

In view of the relation of the surface oxidation and emissivity, the work of this paper aims to measure the spectral emissivity during the annealing of alloy steel under conditions favourable for selective oxide formation. By employing a spectrometer in long wavelength infrared (LWIR) bands where vibrational spectral features of selective oxides are present, spectral information related to $\mathrm{Mn}-\mathrm{O}$, Al-O and Si-O could be obtained. Characterization of postannealed samples is carried out subsequently. 


\subsection{1/qirt.2016.041}

\section{Experiment set up and data processing}

IF (standard steel), TRIP and HF samples after cold rolling are heated by means of Joule effect in a black cavity (see Figure 1) purged with $\mathrm{H}_{2}+\mathrm{N}_{2}$ gas. The varied dew points are $-38^{\circ} \mathrm{C},-28^{\circ} \mathrm{C},-16^{\circ} \mathrm{C}$ and $-6^{\circ} \mathrm{C}$. The heat rate is set at $2.2^{\circ} \mathrm{C} / \mathrm{s}$ to attain $860{ }^{\circ} \mathrm{C}$ where the temperature is maintained for a soaking period of $129 \mathrm{~s}$. Thereupon, the sample was allowed to cool to room temperature. The cooling rate is around $10^{\circ} \mathrm{C} / \mathrm{s}$.
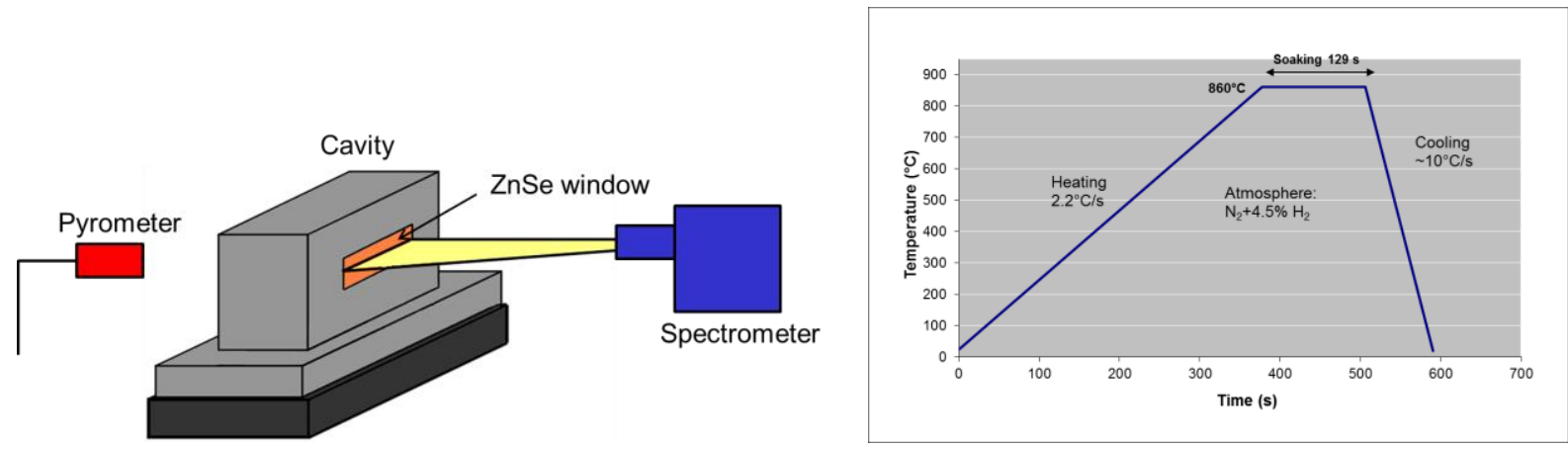

Fig. 1. Experimental set up (left) and thermal cycle (right)

One side of the sample is covered with black paint. This is used for temperature regulation by a fibered pyrometer through a quartz window. Through the front ZnSe window, direct signal measurement by the LWIR spectrometer is conducted. Each set of experiment is repeated at least twice.

Data preprocessing steps include radiometric calculation based on real-time temperature measurement and spectral response of spectrometer. The sample temperature is used to calculate the wavelength-dependent Planck's radiance. Using previous black body calibration results to take into consideration of the spectral response of the spectrometer, the corresponding black body signal is computed. The mean intensity within the homogeneous heating zone is taken. To reduce noise, a moving average with a window size of $0.6 \mu \mathrm{m}$ in the spectral axis is applied. The sample signal is then normalised with the computed black body signal (subjected to same moving average preprocessing step) to obtain the emissivity.

\section{Results}

The emissivity during the heating and soaking stage for IF, TRIP and HF at different dew points (DP) is presented in Figure 2 and 3 . Figure 2 shows the global emissivity, i.e. the ratio of the sample signal in the entire wavelength range of 8-12 $\mu \mathrm{m}$ over a black body signal at the same temperature. More detailed spectral evolution is illustrated in figure 3 . The left side displays the spectral emissivity obtained at temperatures around $490{ }^{\circ} \mathrm{C}, 585^{\circ} \mathrm{C}$ and $750{ }^{\circ} \mathrm{C}$ during the heating stage while the right side shows the emissivity spectra at the start, middle and end of the soaking stage. The same interval is applied for each set of IF, TRIP and HF curves to facilitate comparison between the different steel grades.

After annealing, the infrared spectra of the samples are measured by a Jasco FTIR spectrometer in specular reflection mode at an incidence angle of $85^{\circ}$. The DTGS detector is employed. The absorbance spectra of TRIP and HF samples (offset for clarity) are shown in figure 4 and 5 respectively.

\section{$3.1 \quad$ IF}

During the heating of an IF steel at dew point (DP) $-6{ }^{\circ} \mathrm{C}$ and $-38{ }^{\circ} \mathrm{C}$, the global level of emissivity increases monotonically. During the soaking stage where the temperature is maintained at $860^{\circ} \mathrm{C}$, the level of emissivity remains constant. Similar shape of the emissivity spectra during both stages is observed. Under these atmospheric conditions and above $400{ }^{\circ} \mathrm{C}$, it is thermodynamically favourable for the reduction of iron oxides to iron [3]. Thus, native iron oxides are reduced. However, no spectral features are observed in this wavelength range $(8-12 \mu \mathrm{m})$ because the infrared-active vibrations of iron oxides (magnetite, maghemite, hematite, wüstite) lie beyond $17 \mu \mathrm{m}$. Infrared spectra of annealed IF samples measured by FTIR show no significant peaks in the wavelength range of $5-25 \mu \mathrm{m}$, confirming the absence of iron oxides after annealing.

\section{$3.2 \quad$ TRIP}

From the global emissivity curves of TRIP steel (1-2\% of $\mathrm{Al}$ and $\mathrm{Mn}$ respectively), the different dynamics obtained at different DP are distinguishable, especially during the soaking stage. At $\mathrm{DP}=-6^{\circ} \mathrm{C}$, the emissivity continue to 


\subsection{1/qirt.2016.041}

increase during the soaking stage while at $\mathrm{DP}=-38^{\circ} \mathrm{C}$, it decreases slightly. The emissivity spectra show change in slope and appearance of broad bumps at the vicinity of $10,10.5,10.8 \mu \mathrm{m}$. These correspond to the IR vibrational signatures of aluminium oxides and Mn-Al mixed oxides. The presence of these oxides is confirmed by FTIR (see Figure 4), where absorption peaks at $10.2 \mu \mathrm{m}$ and $11 \mu \mathrm{m}$ are detected for annealed samples, whereas no peaks are observed on a pre-annealed sample. The broad bump for $\mathrm{DP}=-6^{\circ} \mathrm{C}$ and $-16{ }^{\circ} \mathrm{C}$ sample from $17-20 \mu \mathrm{m}$ could be associated with $\mathrm{Mn}-\mathrm{O}$ or Fe-O. Observation of DP $=-6{ }^{\circ} \mathrm{C}$ sample under FE-SEM (Figure 6) shows bright grains where Fe is mainly detected in EDX and gray phase rich in $\mathrm{Mn}$ and $\mathrm{O}$. The residual bright phase also consists mainly of Fe. The bright grains are assumed to be reduced iron that measure up to $1 \mu \mathrm{m}$, uniformly distributed across the surface with higher concentration around grain boundaries and cracks. The surface height measured by AFM in figure 7 illustrates the topographical effects of the grains which introduce an additional roughness aspect. Backscattered electron (BSE) image and AFM height image of DP $=-38{ }^{\circ} \mathrm{C}$ sample display more homogeneous surface morphology which appears film-like. EDX analysis shows an enrichment of $\mathrm{Al}$ and $\mathrm{O}$.

\subsection{HF}

The global emissivity of HF steel increases during heating till the temperature reaches around $650{ }^{\circ} \mathrm{C}$ and decreases to a local minimum at around $740{ }^{\circ} \mathrm{C}$ before increasing again. It was reported that the formation of $\mathrm{MnO}$ begins at $500-650{ }^{\circ} \mathrm{C}$ and as temperature increases, transformation to Si-Mn mixed oxides occurs [5], [9]. The emissivity spectra during the soaking stage show higher increase of emissivity at wavelength bands $8,8.5$, $9 \mu \mathrm{m}-$ where IR vibrational of silicon oxides are expected - than at longer wavelengths. Generally, the emissivity of HF is higher throughout the wavelength range of $(8-12 \mu \mathrm{m})$ than IF and TRIP. FTIR spectra of the annealed samples in figure 5 show significant peaks at 10,11 and $17 \mu \mathrm{m}$ which indicate the presence of individual and/or mixed oxides of $\mathrm{Mn}, \mathrm{Al}$ and $\mathrm{Si}$. EDX results also show enrichment of $\mathrm{Mn}, \mathrm{Al}, \mathrm{Si}$ and $\mathrm{O}$ while the BSE image shows variation of grayscale, suggesting mixed oxide species with darker phase richer in Si-Mn mixed oxides.
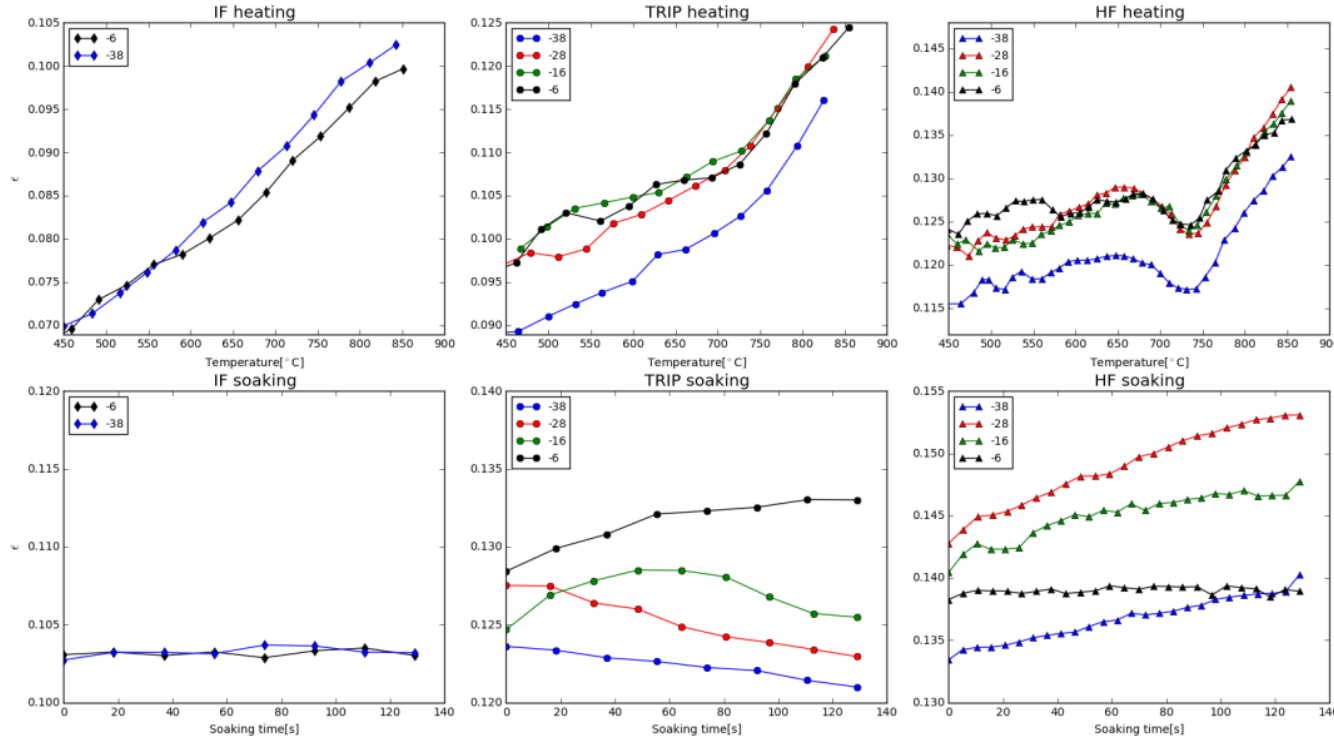

Fig. 2. Global emissivity $(\lambda=8-12 \mu \mathrm{m})$ of IF, TRIP, HF steel during heating and soaking at $D P=-38{ }^{\circ} \mathrm{C}$ to $-6{ }^{\circ} \mathrm{C}$ 

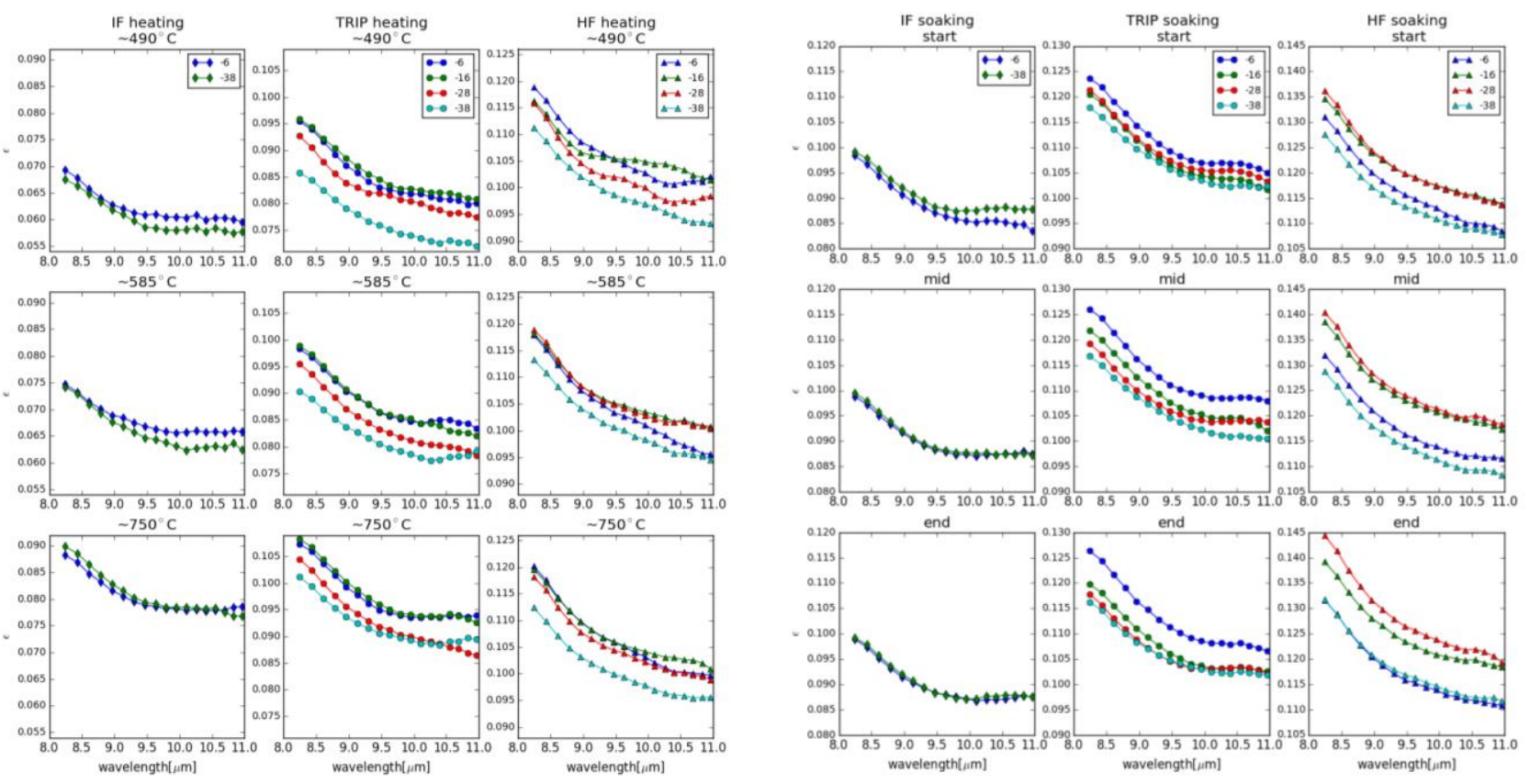

Fig. 3. Spectral emissivity of IF, TRIP, HF steel during heating and soaking at $D P=-38{ }^{\circ} \mathrm{C}$ to $-6^{\circ} \mathrm{C}$

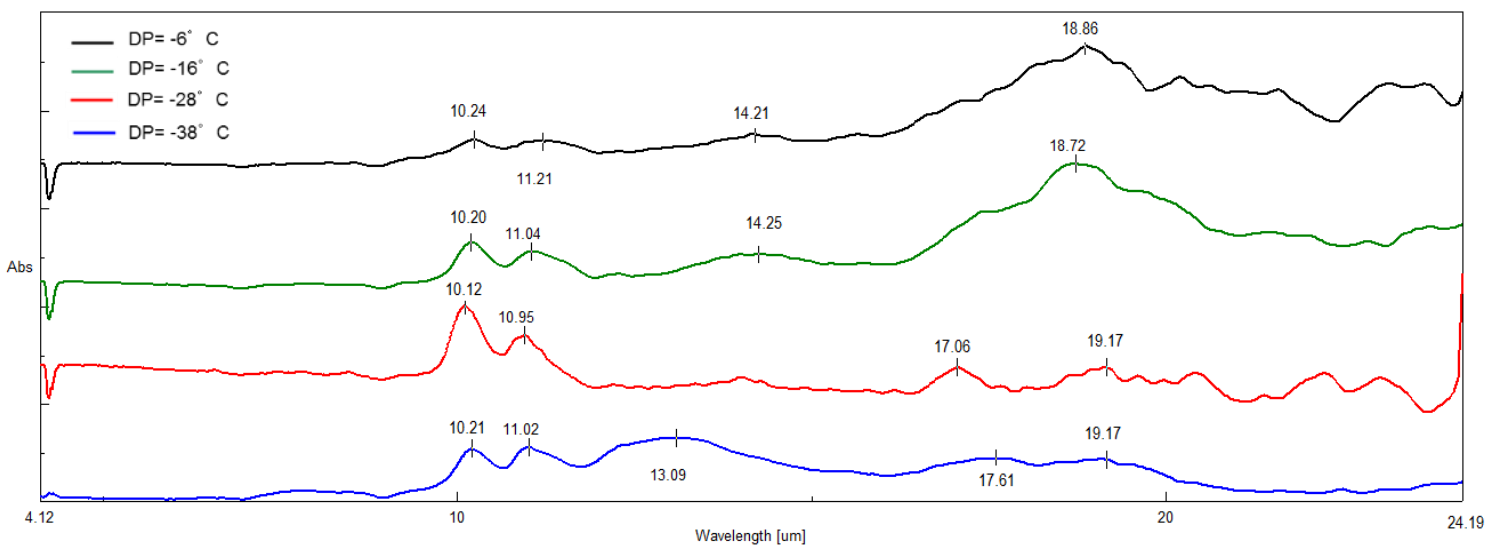

Fig. 4. FTIR absorbance spectra of TRIP annealed at $D P=-38^{\circ} \mathrm{C}$ to $-6{ }^{\circ} \mathrm{C}$ 


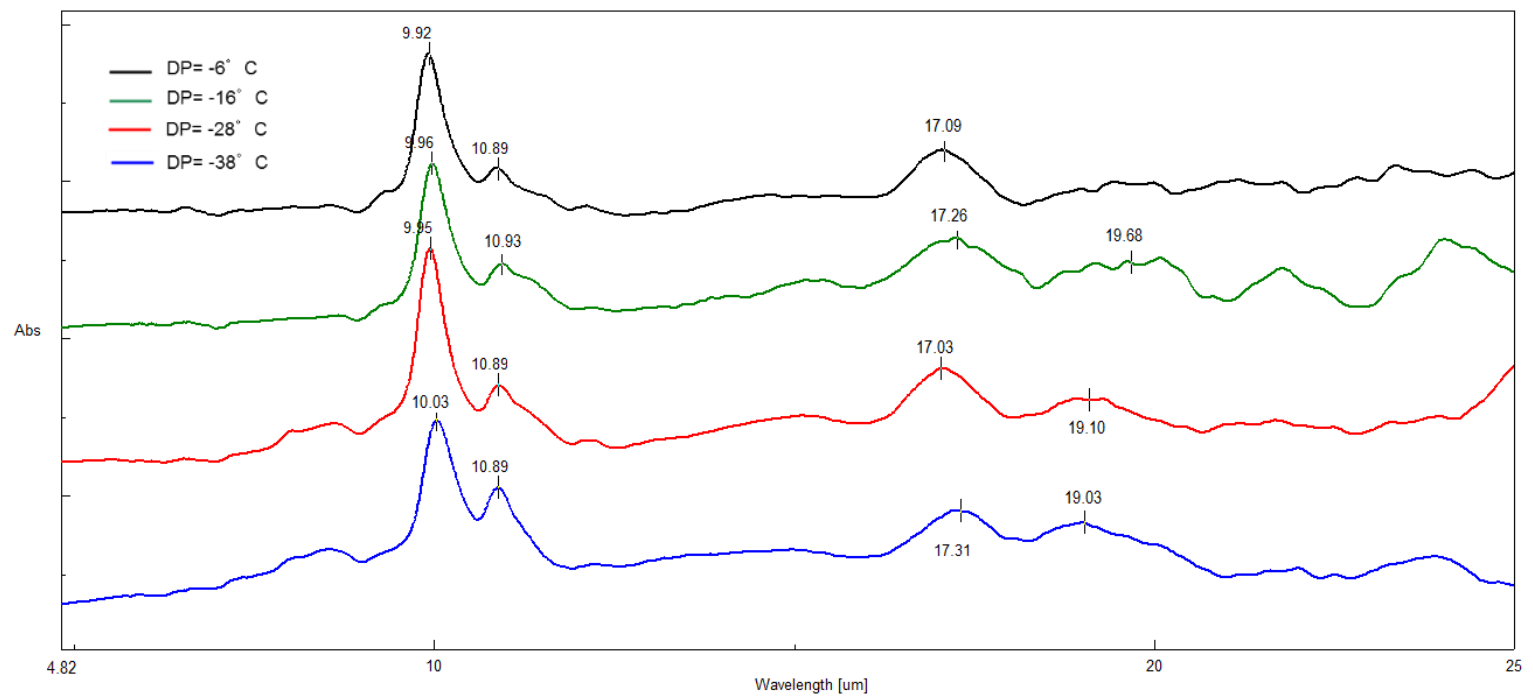

Fig. 5. FTIR absorbance spectra of $H F$ annealed at $D P=-38{ }^{\circ} \mathrm{C}$ to $-6{ }^{\circ} \mathrm{C}$
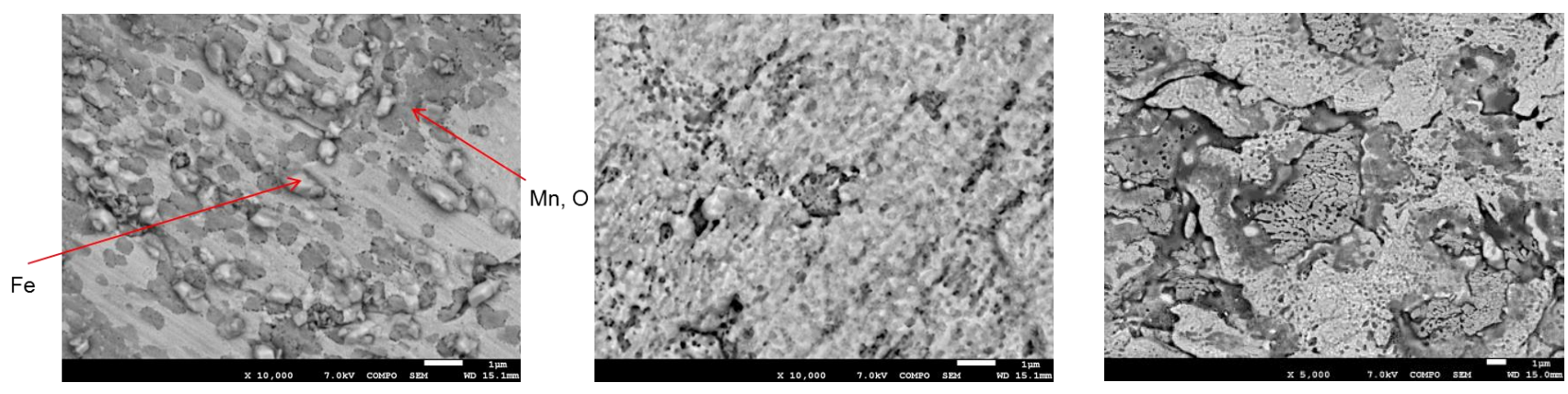

Fig. 6. Backscattered electron images of the surface of annealed TRIP at $D P=-6{ }^{\circ} \mathrm{C}(\mathrm{left}), \mathrm{DP}=-38^{\circ} \mathrm{C}($ middle) and $H F$ at $D P=-28^{\circ} \mathrm{C}$ (right)
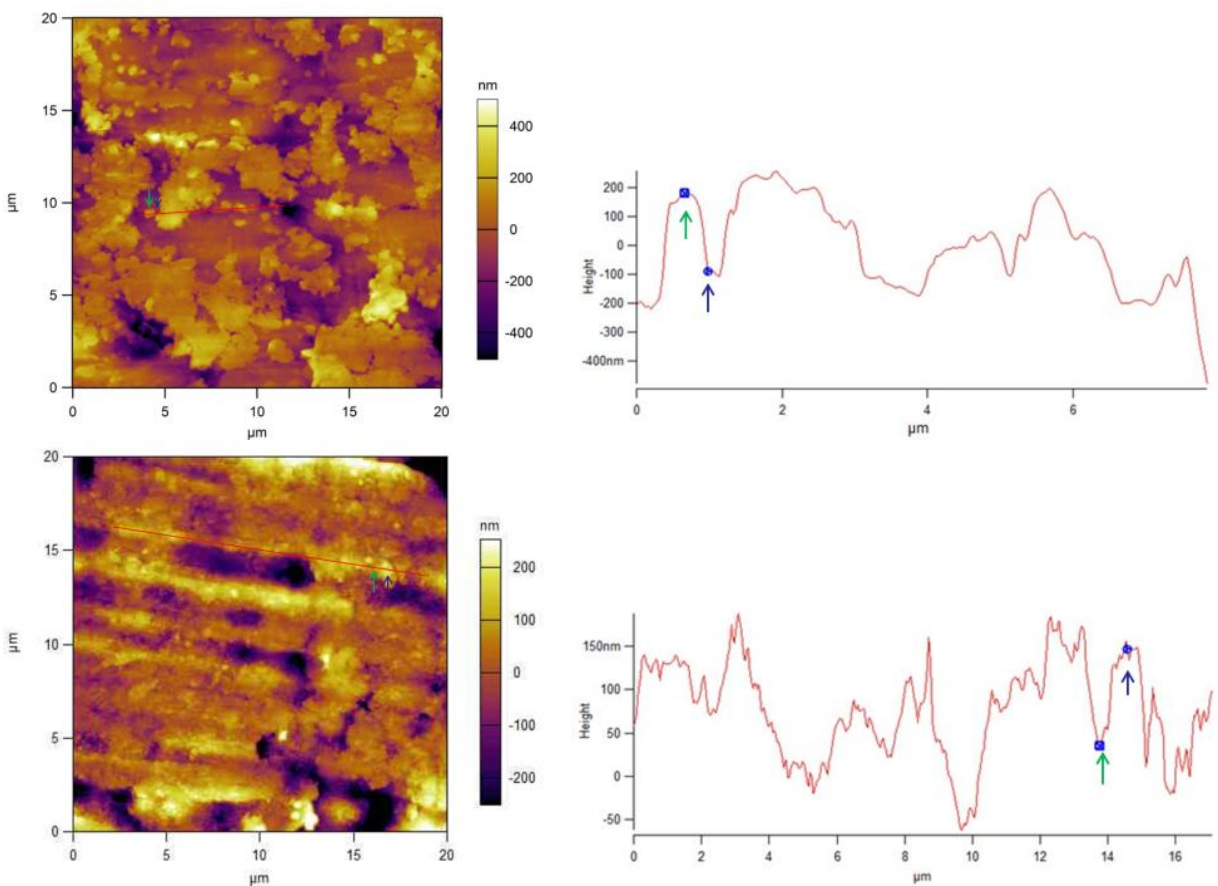

Fig. 7. AFM height images and roughness profile of drawn red line: Annealed TRIP at $D P=-6^{\circ} \mathrm{C}$ (top) and $D P=-38^{\circ} \mathrm{C}$ (bottom) 


\section{Discussion}

Oxide-free standard steel (IF) has a low emissivity of around 0.10 in the wavelength range of $8-12 \mu \mathrm{m}$. The emissivity value stays constant during isothermal soaking. The emissivity of TRIP steel during soaking varies depending on the dew point (DP) of the controlled atmosphere due to the varying physicochemical state that is later confirmed in FTIR absorption spectroscopy. Although surface sensitive analysis from FTIR (at a grazing angle of $85^{\circ}$ ) shows lowest peak at 10.2 and $11.2 \mu \mathrm{m}$, the emissivity of $\mathrm{DP}=-6^{\circ} \mathrm{C}$ is the highest among the TRIP samples. This could be explained by the formation of internal oxides with higher concentration of oxides beneath the surface, which is typical for TRIP steel annealed at high dew point [1]. This could lead to the increase of infrared penetration depth and contribution of the overall emissivity by a bigger volume, which accounts for the higher emissivity. Higher DP favours the formation of manganese oxides while lower DP favours the formation of aluminium and Mn-Al mixed oxides on the surface. In the case of HF steel, the highest emissivity is measured for sample annealed at DP $=-28{ }^{\circ} \mathrm{C}$. This corresponds to the highest peak at 10 and $10.9 \mu \mathrm{m}$ shown by FTIR analysis on post-annealed sample. The shape of the FTIR spectra for all $\mathrm{HF}$ samples is similar and the absorption peaks hint the presence of individual and mixed oxides of $\mathrm{Mn}, \mathrm{Al}$ and $\mathrm{Si}$.

Besides the global emissivity, the shape of the spectral emissivity is distinctive for each different grade of steel which is attributed to the presence of different species of oxides. Where Mn-Al oxides and aluminium oxides are present, broad bumps in the emissivity spectra around 10-11 $\mathrm{mm}$ are observed which is in the case of TRIP steel. For HF steels, steeper slopes from 8-9 $\mu \mathrm{m}$ are observed, indicating the presence of silicon (mixed) oxides in addition to other oxides present in TRIP.

The morphology of oxides varies with the annealing conditions. TRIP sample annealed at DP $=-38{ }^{\circ} \mathrm{C}$ shows filmogenic oxides rich in aluminium which is supported by results obtained by Liu et al. [1] and Kim et al. [10]. On the contrary, reduced iron particles and grainy manganese oxides are scattered on the surface of TRIP DP $=-6^{\circ} \mathrm{C}$ sample. According to Wen et al. [8], this additional roughness brought along by the morphology could influence the emissivity which could also account for the higher emissivity of TRIP DP $=-6^{\circ} \mathrm{C}$.

\section{Conclusion}

We demonstrated the measurement of emissivity using LWIR spectrometer during the annealing of IF, TRIP and HF steels under controlled atmosphere. Formation of selective oxides of $\mathrm{Mn}, \mathrm{Al}$ and $\mathrm{Si}$ oxides on the latter two grades of steel results in the change of emissivity. The spectral emissivity shape is dependent on the oxide species associated with steel types and dew points. Since emissivity is influenced by multiple factors, the change in emissivity is interpreted taking into account the chemical composition and roughness. Increased concentration of oxides also increases the infrared penetration depth, resulting in an overall contribution of emissivity by a larger integration volume. The influence of the individual factors on the emissivity is to be investigated further. Nevertheless, the results show that the in-situ characterization method could be implemented in the industry to detect the presence of selective oxides under various annealing atmosphere.

\section{REFERENCES}

[1] H. Liu, Y. He, S. Swaminathan, M. Rohwerder, and L. Li, "Effect of dew point on the surface selective oxidation and subsurface microstructure of TRIP-aided steel," Surf. Coat. Technol., vol. 206, no. 6, pp. 1237-1243, Dec. 2011.

[2] J. M. Mataigne, M. Lamberigts, and V. Leroy, "Selective oxidation of cold-rolled steel during recrystallization annealing," Dev. Annealing Sheet Steels Ed R Pradhan Gupta Miner. Met. Mater. Soc., pp. 511-528, 1992.

[3] H. T. Abuluwefa, "Thermodynamics and Kinetics of Surface Oxidation of Steels during Annealing in H2-N2 Atmospheres," in Proceedings of the International MultiConference of Engineers and Computer Scientists, 2012, vol. 2.

[4] V. A. Lashgari, "Internal and External Oxidation of Manganese in Advanced High Strength Steels," TU Delft, Netherlands, 2014.

[5] T. van de Putte, Z. Zermout, D. Loison, S. Claessens, and J. Penning, "Selective Oxidation during the Austenitic Annealing of a CMnSi Steel," Adv. Mater. Res., vol. 15-17, pp. 129-134, 2007.

[6] R. B. P.-S. Leire del Campo, "Iron oxidation kinetics study by using infrared spectral emissivity measurements below $570^{\circ}$ C," Corros. Sci., vol. 50, no. 1, pp. 194-199, 2008.

[7] K. J. D. C. Shi, "Spectral emissivity characteristics of the Usibor® 1500P steel during austenitization in argon and air atmospheres," Int. J. Heat Mass Transf., vol. 91, pp. 818-828, 2015.

[8] C.-D. Wen and I. Mudawar, "Modeling the effects of surface roughness on the emissivity of aluminum alloys," Int. J. Heat Mass Transf., vol. 49, no. 23-24, pp. 4279-4289, Nov. 2006. 


\subsection{1/qirt.2016.041}

[9] R. Sagl, A. Jarosik, G. Angeli, T. Haunschmied, G. Hesser, and D. Stifter, "Tailoring of oxide morphology and crystallinity on advanced high-strength steel surfaces prior hot-dip galvanizing," Acta Mater., vol. 72, pp. 192-199, juin 2014.

[10] Y. Kim, J. Lee, K.-S. Shin, S.-H. Jeon, and K.-G. Chin, "Effect of dew point on the formation of surface oxides of twinning-induced plasticity steel," Mater. Charact., vol. 89, pp. 138-145, Mar. 2014. 